\title{
The Use of Unified Message System as a Vehicle for Effective Mobile Business Communication: The Case of Morpheus Message
}

\author{
Wooseok Jung ${ }^{1}$, Byungwook Kim¹, Sangwoo Shin ${ }^{2}$ \\ 'Uracle, Seoul, Korea \\ ${ }^{2}$ Woosong University, Daejeon, Korea
}

Objectives: Message integration has played a crucial role in executing a delivery of more relevant and meaningful business messages in the cluttered communication environment. This paper introduces Morpheus Message, a unified message system developed by Uracle, and illustrates its operational characteristics. This paper also presents conceptual discussions on how Morpheus Message can facilitate effective business communications.

Methods: The main focus of message integration in both academia and practice has shifted from a company-driven perspective to a customer-driven one. This paradigm shift suggests that the main motive for well-coordinated/integrated messages is message relevance and meaningfulness to the target customer audience, not managerial convenience gained through a centralized message distribution. This paper forwards not only the conceptual justifications for the key operational characteristics of Morpheus Message, but a practical example of how it successfully serves as a platform of mobile message integration.

Results: The practical application of Morpheus Message shows that the client company who switches to it from a legacy message distribution system enjoys a 50\% reduction in annual delivery costs despite the steady growth of its customer base. The use of Morpheus Message also enables the client company to supply its target audience with more demanded and relevant information, thereby reinforcing existing service channels and/or establishing new ones.

Conclusions: The case of Morpheus Message described in this paper sheds light on how the use of a unified message system can facilitate more effective business communications and expand new service opportunities in the mobile business environment.

Key Words: Mobile Communication, Business Messaging Service, Message Clutter, Message Integration, Unified Message System

Received: Nov 14, 2021 Revised: Jan 6, 2022 Accepted: Jan 14, 2022

Corresponding author: Sangwoo Shin

Solbridge International Business School, Woosong University, 128 Uam-ro, Dong-gu, Daejeon 34613, Korea

Tel: +82-42-630-8547, E-mail: sangwoo.shin@solbridge.ac.kr

This is an Open Access article distributed under the terms of the Creative Commons Attribution Non-Commercial License (http://creativecommons.org/licenses/ by-nc/4.0/) which permits unrestricted non-commercial use, distribution, and reproduction in any medium, provided the original work is properly cited.

Copyright ( $\odot 2022$ Korean Association for Business Communication.

\section{Introduction}

Since the introduction of the iPhone in 2007, smartphones have become a daily necessity to many people all over the world. In Korea, the adoption rate of smartphones has steadily increased from 53.4\% in Jan 2012 to $93.4 \%$ in June 2021 (Gallup Korea, 2021). The smartphone, thanks to its widespread use and technological convenience, has emerged as a central device for mobile business communications. The companies, in a variety of industry domains including healthcare, finance, education and public sector, seek for new business opportunities by estab- 
lishing and leveraging mobile communication channels with their customers. This trend has been fueled even further by the outbreak of Covid-19 in 2019. The mandated social distancing dramatically increases the volume of non-face-to-face communications, leading to a society-wide improvement of digital literacy. More people now feel less reluctant to use a smartphone as a non-face-to-face communication device and, correspondingly, the role of mobile communication in the business context becomes more profound.

The demand for mobile business communication leads naturally to a boom in the telecommunication service market, which in turn proliferates its related value-added service industries. The number of special value-added telecommunication service providers has been more than doubled from 372 in 2016 to 787 in 2021 (Central Radio Management Service, 2021). One of the fast-growing value-added telecommunication services is business messaging service, of which the sales volume has grown at a rapid pace from 300 billion KRW in 2009 to 1.7 trillion KRW in 2020 (Kim, 2021). In conjunction with the rapid expansion of business messaging service, more emphasis has been placed on its role as a channel for more effective business communication.

Business messages have been sent to customers through a diverse set of communication media encompassing (1) traditional broadcasting channels such as TV and radio, (2) direct marketing channels such as mail, phone, fax and email, and (3) relatively new mobile channels in the form of short message service (SMS), App/Web Push notifications and rich communication service (RCS). No matter what media channel is used for business messaging, its basic functionality is to execute one-directional delivery of information from a company to its customers. A strong impetus for effective business communication requires business messaging service to play a role beyond its basic functionality. The desired role of business messaging service is to facilitate two-way interactions with customers, which in turn is translated into more business opportunities. In alignment with customer feedbacks received through a two-way communication channel, companies are able to redesign existing services and/or offer new services.

Another issue for effective business communication is how to break through message clutter (Elliot \& Speck, 1998; Ha \& McCann, 2008; Pieters, Warlop, \& Wedel, 2002). Given the prominence of mobile business communication, customers likely receive the excessive number of messages from a number of different companies on a daily basis. Customers get overwhelmed easily with tons of intrusive messages that may cause a negative predisposition towards message senders. The cluttered message environment has made it increasingly harder to attract and hold customers' attention to the delivered messages, signifi- cantly impairing the effectiveness of business communication. Consequently, it is imperative to avoid or minimize message clutters for companies to keep benefiting from business communication.

A key theme that naturally arises for effective business communication is message integration (Ake \& Grönroos, 2009) within the general framework of Integrated Marketing Communication or IMC in short (Brian, 2012; Groom, 2008; Killian \& McManus, 2015; Kitchen, Brignell, \& Jones, 2004; Schultz \& Barnes, 1999). The central idea behind message integration is that well-coordinated/integrated messages are more likely to cut through message clutter and thereby more viewable, which can further create "meaning" on the receiver. Shedding light on this meaning creation role of message integration, Ake and Grönroos (2009) conceptualizes four major factors that message integration process should take into consideration: (1) historical (i.e., history of previous communications), (2) future (i.e., expectation of future relationship with the message sender), (3) internal (i.e., personal traits such as attitudes, capabilities, and personal interests) and (4) external factors (i.e., culturally situated factors such as trends, traditions, economic situation, and messages from competition). The former two factors correspond to a temporal dimension of meaning creation, while the latter two factors relate to a situational dimension of that. Both temporal and situational factors matter to make the messages sent more relevant and meaningful.

The aforementioned conceptual view forwards a key insight into designing and developing a unified message system (UMS henceforth). That is, an UMS should be designed and developed in a more customer-centric way. The operational implementation of this idea then requires an UMS to provide an extra value-added functionality that goes beyond a simple horizontal integration of fragmented messages across multiple channels. Two examples of this value-added functionality are (1) a vertical integration over message lifecycle and (2) a tracking capability of customer reactions. Morpheus Message, an UMS of primary interest in this paper, builds upon the customer-centric design and possesses these two operational characteristics. More detailed discussions will follow in the Discussion section after descriptions of what Morpheus Message is and how it works for more effective mobile business communications.

\section{Case Description}

This section describes the case of Morpheus Message, a commercial UMS adopted by many client companies in a variety of industries. The case study begins with providing its background information and moves on to illustrating the operational char- 
acteristics of Morpheus Message. An introduction of its practical application example then follows.

\section{Backgrounds}

Uracle is a service platform company starting its business in 2001 by offering a PDA-based stock transaction service. Since the inception, Uracle has accumulated a single-source mobile technology applicable to a variety of operating systems. Thanks to this technological achievement, Uracle successfully launched Morpheus Message in 2011, a mobile service system for message integration. Since then, the share of Morpheus Message in the mobile messaging market has steadily increased. Eventually, Uracle becomes a leading service provider of mobile message platform in Korea with more than 500 client companies. The client list includes major companies in a diverse set of industries ranging from LG U+ (telecommunication service) to SK Innovation (energy industry) to Korea Post (public postal service). This paper briefly summarizes the case of Korea Post to explore the potential benefits of adopting and implementing an UMS such as Morpheus Message.

\section{Operational Characteristics of Morpheus Message}

The prevailing UMSs in the market are designed mostly to integrate multiple message channels operated independently within a single company. The key expected benefit of adopting such an UMS is to enhance managerial efficiency through a centralized control over a number of fragmented message channels. Lacking here is a motive for using an UMS as a vehicle for effective communications with customers. This customer-centric motive underlies the development of Morpheus Message.

Morpheus Message has a number of unique characteristics that together differentiate itself from alternative mobile message systems. The diagram portrayed in Figure 1 graphically conceptualizes Morpheus Message. Two distinguished features of Morpheus therein are (1) integration over message lifecycle and (2) two-way communication, both of which are elaborated further in the sequel.

\section{Integration over Message Lifecycle}

A message has its own lifecycle, that is, it experiences multiple stages over its lifespan from creation to delivery. More specifically, message lifecycle starts with creating an electronic template in the form of text, image, and multimedia, and moves on to managing campaign or contents for personalized distribution. Then, the selection of a message delivery channel (e.g., mail, fax, email and mobile push/messenger/text) as well as a message delivery type (e.g., sequential, continuous, automatic and batch) follows before a message delivery is finalized. Morpheus seamlessly integrates these tasks performed throughout the entire message lifecycle within a single system and conducts them in a well-coordinated/integrated fashion. This contrasts Morpheus Message starkly with other prevailing systems that focus primarily on a unified message distribution by integrating multiple channels horizontally.

\section{Two-Way Communication}

The successful delivery of a message to the target customer is the end of the story, if a message distribution system is used only as a vehicle for one-way communication. It, however, can be the beginning of a new story in the context of two-way communication. Morpheus Message conducts a real-time collection of customer responses to a message delivery. A set of basic functionalities embedded within Morpheus Message makes it possible to check (1) whether the messages have safely arrived

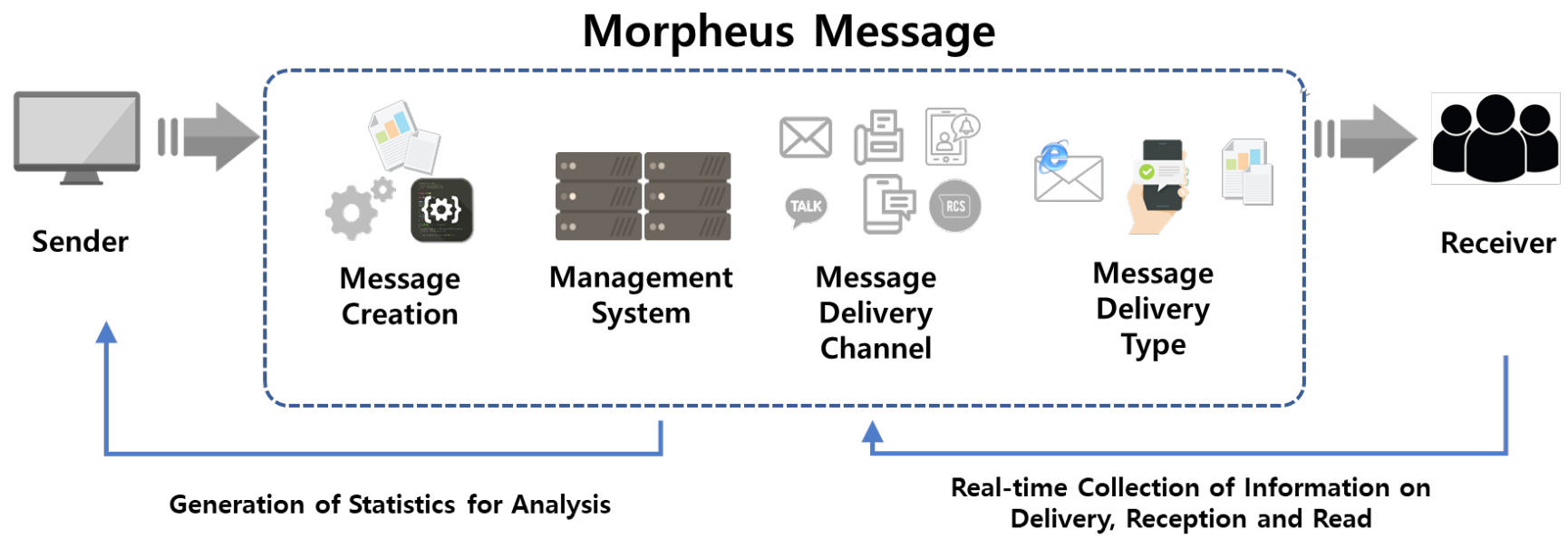

Figure 1. Graphical conceptualization of morpheus message. 
at the receiver's mobile device and (2) whether the receiver has opened and/or read them. Utilizing these functionalities, Morpheus Message can refine its operation with an aid of customer feedbacks.

This interactive nature makes it easier to use Morpheus Message as a vehicle for effective business communication. An example is its ability to detect if no response results from deletion of the mobile application. In such a case, Morpheus Message sends the receiver an application-free message such as push and SMS to encourage the user to reinstall the deleted application. By doing so, Morpheus Message can revitalize the linkage to those who are almost lost and let them stay connected longer. Another example is a cost-efficient implementation of sequential message delivery. Figure 2 presents an example of cost-efficient sequential message delivery. Different mobile channels vary in their delivery costs per message: free for push, 7.5-20 KRW for messenger talk (e.g., Kakao talk) and 8-55 KRW for various xMSs including SMS, LMS, and MMS. Given this hierarchical cost structure, Morpheus Message pursues a lowest-cost channel first, switches to the next one if the first trial fails to reach the target customer, and repeats this procedure until the success. The resulting delivery rate is impressive and almost near to $100 \%$. There is also great potential for cost saving if most of the target customers are reached with a lowcost option.

Furthermore, the collection of customer response information generates a number of useful customer-level summary statistics such as recency and frequency of application usage and access. The subsequent data analysis allows Morpheus Message not only to optimize the frequency and speed of message delivery at the individual customer level, but to find new service opportunities by managing a long-run relationship with customers. Lastly, it is worthwhile to mention that Morpheus Message is a system flexible enough to embrace a number of add-on modules. One of the add-ons, particularly important to two-way communication, is a survey module (i.e., Morpheus Survey), through which the company can listen to very detailed voices of its customers.

\section{Practical Application of Morpheus Message: An Example of Korea Post}

Morpheus Message, characterized by the two distinguished features discussed earlier, is appealing particularly to the companies who have used a single message channel with a low delivery rate or multiple yet fragmented message channels that often incur message leakages due to untargeted delivery, delivery errors, reception blocking and duplicated delivery. Since its introduction in 2011, Morpheus Message has served more than 500 client companies, out of which this paper boils down to the case of Korea Post.

Korea Post is a public postal service provider in Korea, who has a long history of operation since 1884 and is operating a nation-wide network of approximately 3,400 post offices. Korea Post offers a variety of financial services on top of its core postal services. The nature of its business leads Korea Post to send a massive volume of messages to its customers such as tracking information of postal deliveries, advertising of financial products, and so on.

Korea Post had three key reasons for upgrading its existing message distribution system. First, message delivery costs have increased by $10 \%$ every year, due mainly to a steady expansion of the customer base. Driven by this cost saving motive, Korea Post sought for a new system that can reduce delivery costs per message and/or improve delivery rates for a given cost amount. Second, Korea Post had a considerable need to upgrade a platform for "smart" financial services. As Korea Post relied primarily upon mobile text messages (e.g., SMS/LMS) for this purpose,

\section{Cost per message Message Delivery Channel}

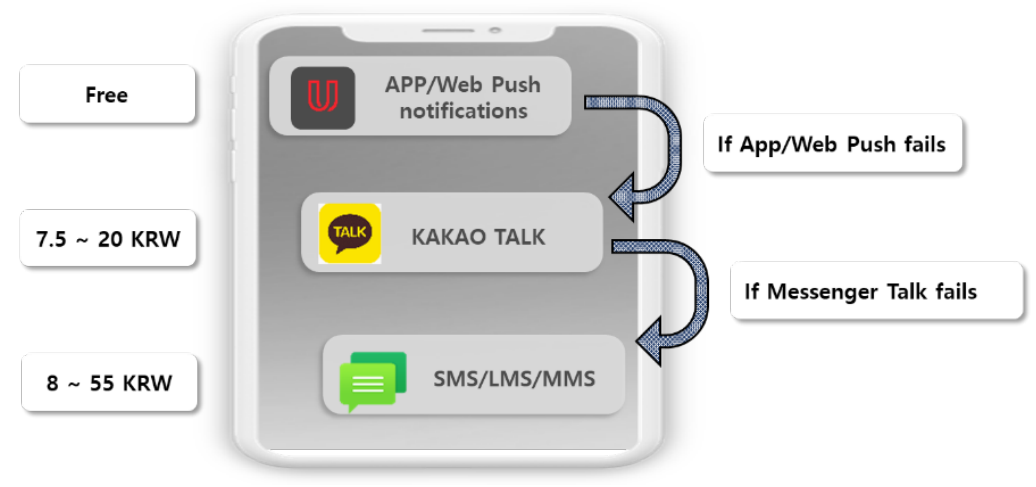

Figure 2. An example of cost-efficient sequential message delivery. 
it would like to diversify into new message channels and, in doing so, collect meaningful marketing data. At the same time, Korea Post demanded a system that can use messages as a communication vehicle to reinforce customer services and improve customer satisfaction. Third, Korea Post had a strong demand for a single unified system of multiple channels that allows for in-house management. Korea Post selected Morpheus Message as an all-in-one solution to address these three issues altogether.

Migration to Morpheus Message from the legacy system started August 2019 and the first phase of the entire project was completed by the end of 2019. Since the adoption of Morpheus Message, the resulting performance improvement thus far has been very impressive. Korea Post has enjoyed a 50\% reduction in annual delivery costs, which would be a $10 \%$ increase otherwise. The use of Morpheus Message further enables Korea Post to send more demanded and relevant information to its target audience, thereby reinforcing existing service channels and/or establishing new ones. The subsequent data analysis based on a variety of statistics provided by Morpheus Message derives new marketing insights and assists the planning of new marketing campaigns. The client company, Korea Post, is quite motivated by these tangible benefits so that the project proceeds to the next phase where the main target is to integrate the direct marketing channels into Mopheus Message.

\section{Other Practical Applications of Morpheus Message}

Other than the Korea Post case described above, Morpheus Message has been adopted by a number of client companies: to name a couple, (1) Hankook Tire and (2) HDC I-Park Mall. The former company uses Morpheus Message mainly to establish an easy-to-use mobile membership channel for more customer acquisition, while the latter company uses it primarily to offer an effective mobile service channel for more customer retention. In both cases, Morpheus Message contributes to the efficient operation of the company's customer membership program, pointing to the possibility of using Morpheus Message as a vehicle for better customer relationship management.

\section{Discussion}

\section{Customer-Centric Design of Message Integration Platform}

The focus of message integration in the IMC literature has shifted from company-driven perspective (Duncan, 2005; Pickton \& Broderick, 2005; Shimp, 2007) to customer-driven one. This customer-centric view highlights the idea that it is customers, not companies, who integrate message. In practice, there has been a growing tendency among major financial companies to adopt an UMS to integrate a number of existing fragmented message channels. The main motive for this movement, however, has been limited largely to managerial convenience gained through a centralized control over multiple channels. It is imperative to place customers at the center stage in the course of designing and developing an UMS.

The operational implementation of this customer-centric idea requires an UMS to provide an extra value-added functionality that goes beyond a simple horizontal integration of fragmented messages across multiple channels. An example of this value-added functionality is a vertical integration over message lifecycle. A message experiences multiple stages over its life span from creation to delivery. If the tasks required throughout the entire message lifecycle are performed in a well-coordinated/integrated fashion within a single UMS, the UMS serves as a holistic message integration vehicle that manages both horizontal and vertical dimensions of messaging. Correspondingly, the relevance and meaningfulness of messages can be maintained more consistently.

Another example of the value-added functionality is a tracking capability of customer reactions. It is practically daunting to align company's message campaign with customer's situational factors (i.e., both internal and external factors described by Ake \& Grönroos (2009)), because they are not directly observable to the company. Instead, it is technically feasible to monitor customer responses to the delivered messages that can serve as a proxy for the situation factors. An UMS equipped with a tracking capability of customer reactions, therefore, is a necessary condition for executing customized message campaigns. A key by-product of operating an UMS with this technology is to feed valuable customer-level information that can address customer's temporal factors (i.e., both historical and future factors described by Ake \& Grönroos (2009)) in the middle of designing and developing a message campaign. This further helps companies maintain a long-run relationship with their customers that can be translated into new service opportunities.

Morpheus Message, an UMS introduced in this paper, is designed consistently with the customer-centric idea. Its operational characteristics, featured by (1) integration over message lifecycle and (2) two-way communication, support implementation of this customer-centric idea in the context of mobile business communication. Correspondingly, Morpheus Message sheds light on the possibility of using an UMS as a vehicle for effective mobile business communication.

\section{Future of Unified Message System}

Morpheus Message opens a new avenue for the use of UMS as a communication vehicle. The functionality of Morpheus Message, however, is neither comprehensive nor perfect in its cur- 
rent form. What needs to be further improved is the inclusion of data analytics. Currently, Morpheus Message uses customer response data mainly to enhance its operational efficiency, but not to support higher-level managerial decisions. Even though Morpheus Message provides a set of descriptive statistics for that purpose, their support is indirect at most in the sense that managerial decisions are made manually and outside of the system. The automated generation of analytical results used for the prescriptive purposes can generate a substantial amount of value-added. Since Morpheus Message has a highly flexible system, its extension towards this direction is not very technically challenging. Thus, it is not very far in the future to see an UMS equipped with various machine learning algorithms (e.g., recommendation engines). If this is the case, one can use an UMS as a decision support vehicle as well as a communication vehicle.

\section{Conclusion}

Business communication has relied heavily upon the use of a mobile device over its traditional counterparts as a primary communication channel. Various attempts have been naturally made to innovate the mobile business communication. Message integration arises as a central idea in academia for effective business communication, necessitating the development of a platform or system to realize it in practice. This paper introduces Morpheus Message, a message unification system developed by Uracle, and illustrates its operational characteristics. The key focus is on discussing how Morpheus Message can facilitate effective business communications. Both the conceptual underpinnings behind Morpheus Message and its practical application discussed in this paper shed light on how the use of a message unification system can make business communication more effective and expand new service opportunities in the mobile business environment.

\section{References}

Ake, F., \& Grönroos, C. (2009). Rethinking marketing communication: From integrated marketing communication to relationship communication. Journal of Marketing Communications, 15(2-3),
179-195.

Brian, G. S. (2012). Communication integration: An analysis of context and conditions. Public Relations Review, 38(4), 600-608.

Central Radio Management Service. (2021, Febury 25). Annal report on radio management statistics. Retrieved from https:// www.crms.go.kr/lay1/bbs/S1T103C104/L/54/list.do

Duncan, T. (2005). Principles of advertising \& IMC (2nd ed.). New York, NY: McGraw-Hill Irwin.

Elliot, M. T., \& Speck, P. S. (1998). Consumer perceptions of advertising clutter and its impact across various media. Journal of Advertising Research, 38(1), 29-30.

Gallup Korea. (2021, June 8). Research on 2012-2021 smartphone adoption rate and brand, smart watch and wireless earphone. Retrieved from https://www.gallup.co.kr/gallupdb/reportContent. asp?seqNo $=1217$

Groom, S. A. (2008). Integrated marketing communication: Anticipating the 'Age of Engage'. Communication Research Trends, 27(4), 3-19.

Ha, L., \& McCann, K. (2008). An integrated model of advertising clutter in offline and online media environment. International Journal of Advertising, 27(4), 569-592.

Killian, G., \& McManus, K. (2015). A marketing communications approach for the digital era: Managerial guidelines for social media integration. Business Horizons, 58(5), 539-549.

Kim, T. Y. (2021, August 3). The business messaging market has become bigger more than 3 times due to the entry of KT and LG U+. Gukjenews. Retrieved from https://www.gukjenews.com/ news/articleView.html?idxno=2279930

Kitchen, P., Brignell, J., Li, T., \& Jones, G. S. (2004). The emergence of IMC: A theoretical perspective. Journal of Advertising Research, 44(1), 19-30.

Pickton, D., \& Broderick, A. (2005). Integrated marketing communications (2nd ed.). Harlow, UK: FT Prentice Hall.

Pieters, R., Warlop, L., \& Wedel, M. (2002). Breaking through the clutter: Benefits of advertisement originality and familiarity for brand attention and memory. Management Science, 48(6), 765781.

Schultz, D. E., \& Barnes, B. E. (1999). Strategic brand communication campaigns (5th ed.). Lincolnwood, IL: NTC Business.

Shimp, T. (2007). Integrated marketing communications in advertising and promotion (7th ed.). Madison, $\mathrm{OH}$ : South-Western. 